\title{
A comédia brasileira nas revistas literárias do pré-modernismo
}

\author{
Maira MARIANO ${ }^{1}$ \\ Universidade de São Paulo - USP
}

\section{A comédia brasileira no século XIX}

A comédia é um gênero literário cujo enfoque recai sobre a realidade cotidiana das pessoas comuns e, segundo Aristóteles, é “uma imitação de homens de qualidade moral inferior". A origem da comédia (do grego Komedia) está ligada aos cortejos festivos em homenagem a Dioniso, cerimônias e canções fálicas, celebrações jocosas após banquetes ou festas.

Surgida no Brasil em meados do século XIX, inicialmente era representada em um ato, entremeando as representações de dramas ou melodramas. Aos poucos, porém, foi incorporada aos palcos nacionais e assumiu o primeiro plano na cena. $\mathrm{O}$ "entremez", como se denominou, foi trazido de Portugal em 1829 pela companhia de Ludovina Soares da Costa e utilizava recursos da farsa: quiproquós, pancadaria, personagens e tipos caricaturais (PRADO, 2003).

A nacionalização do entremez ficou a cargo de Martins Pena, que acrescentou às características farsescas elementos típicos do Brasil. Como bom observador da nossa realidade, o dramaturgo fez um retrato minucioso da nossa sociedade, sobretudo a do Rio de Janeiro.

Em livros de literatura, Martins Pena aparece em pleno Romantismo. No entanto, Décio de Almeida Prado observa que o comediógrafo nada tinha de romântico, apesar de trabalhar com a questão da cor local, pois criticava e satirizava as "atitudes exaltadas e as declarações de amor bombásticas" (Idem, p. 60).

Após essa fase, o Realismo surge para colocar em cena personagens interessados na moral da sociedade burguesa. José de Alencar, notável dramaturgo realista, acreditava que a comédia não podia apenas divertir o público, mas devia servir a um propósito maior: civilizar e fazer refletir sobre os vícios morais e sociais, ou seja, embutir os valores burgueses. Diferenciando-se das comédias de Martins Pena, suas peças já não apresentavam cenas de pancadaria, quiproquós ou os apartes. Seu enredo devia ser o mais

\footnotetext{
1 Professora de Literatura e Língua Portuguesa da Universidade São Judas; graduada em Letras pela Faculdade de Filosofia, Letras e Ciências Humanas - FFLCH/USP; mestre e doutoranda em Literatura Brasileira, pelo Departamento de Letras Clássicas e Vernáculas - FFLCH/USP. E-mail: maira.maria@ig.com.br.
} 
verossímil possível, para isso contava com personagens tirados da vida comum, cenários que sugeriam salas ou cômodos familiares e os atores passaram a utilizar a "quarta parede", criando um clima de "realidade".

“O teatro, encaminhando-se já para a peça de tese, devia não apenas retratar a realidade cotidiana, mas julgá-la, aprovar ou desaprovar o que estaria acontecendo na camada culta e consciente da sociedade” (Idem, p. 80). Décio de Almeida Prado salienta que, apesar de não apresentar uma continuidade histórica perfeita, a comédia de costumes é nossa única tradição teatral. (Idem, p. 117)

Figuram ainda como comediógrafos do século XIX os nomes de Joaquim Manuel de Macedo e França Júnior. Este se consagrou como um escritor crítico, que conseguiu aliar a comédia de costumes à crítica política e social; aquele, embora tenha se destacado mais como romancista, escreveu peças que utilizavam recursos da farsa e outras que se aproximavam das comédias realistas.

Com o passar dos anos, a crítica consagrará essa fase do teatro e verá com desconfiança e desdém o gênero musicado e ligeiro na cena nacional. Até que surjam os primeiros estudos acadêmicos sobre o teatro de revista, como os de Neyde Veneziano, encontraremos na história do teatro brasileiro o "chavão" da decadência do teatro brasileiro. Repetiu-se (e repete-se ainda, infelizmente) a tese de que o teatro considerado sério e de bom gosto perdera espaço nos palcos brasileiros para um teatro "digestivo", de riso fácil, e até pornográfico.

Mesmo Artur Azevedo, tido hoje como um dos grandes comediógrafos brasileiros, não foi poupado pela crítica à época. Reconhecia-se a sua habilidade dramatúrgica, mas lamentava-se que fosse direcionada ao teatro musicado. Artur Azevedo escreveu comédias de costumes, operetas, burletas, revistas de ano, monólogos e cenas cômicas. Mas, de todas essas formas, sobressaiu-se principalmente como autor de operetas, revistas e burletas.

\section{A comédia brasileira nas críticas teatrais do início do século $\mathrm{XX}$}

Em 1865, estreou no Brasil a opereta francesa Orphée aux enfers, música de Offenbach e texto de Hector Crémieux e Ludovic Halévy. O sucesso foi estrondoso e em pouco tempo esse tipo de espetáculo tornou-se o protagonista na cena teatral brasileira. A partir desse acontecimento, as comédias realistas que faziam sucesso no Ginásio Dramático foram, paulatinamente, substituídas pelo teatro musicado e ligeiro no gosto popular. 
É importante fazer essa retrospectiva para entender que a expressão "decadência do teatro brasileiro" surgiu no momento em que a opereta e o teatro de revista se fortaleceram na cena teatral. A ascensão do gênero musicado, para a inquietação dos críticos e intelectuais brasileiros, fez com que as peças consideradas sérias perdessem espaço nos palcos brasileiros. Diante disso, eles passaram a redigir seus textos e colunas afirmando a crença nessa fase "decadente".

Dentre as formas teatrais prósperas no final do século XIX e início do XX figuravam a mágica, a revista e a opereta. E o que essas peças tinham em comum? Além da dança, do cenário grandioso, das cenas apoteóticas, todas são formas de comédia.

Os dramas ou mesmo os melodramas já não atraíam tanto público, salvo quando representados por companhias estrangeiras. As companhias nacionais, a fim de se manter, viram na comédia a sua esperança. Entretanto, não mais aquela de caráter moralizante, pois o público queria rir, cantar e dançar no ritmo do teatro musicado. Para exemplificar, verifiquemos o repertório da Companhia Arruda e o número de vezes em que cada peça foi representada: Uma festa na Freguesia do Ó, 66; São Paulo futuro, 55; Sustenta a nota, 46; Pausinho, 44; Capital federal, 43; Gente moderna, 33; Uma festa em Guabiroba, 32; Divina encrenca, 30; Sem tirar nem pôr, 27; Mulher soldado, 26; Tim Tim por Tim Tim, 25; Picareta, 25; O 32, 25; Caça dotes, 24; Na Piririca, 22; Mambembe, 21; Rosas de Nossa Senhora, 20; O recruta do 43, 20; A grande fria, 20; Pensão D. Ana, 19; Festa do Divino, 18; Sensitiva, 17; Eu digo a ele, 16; Nhô Zé Maria, 16; Mau jeito, 16; São Paulo em fraldas, 15; Almirante negro, 15; Pérola encantada, 14; Na cara do pai, 13; Ribeirão Preto por dentro, 12; Nas horas d'estalar, 11; Periquito, 11; A grande avenida, 11; Visconde de pim pam pum, 10; Casar para morrer, 10; Não lhe bulas, 9; Panaché carnavalesco, 9; Manduca cerimônias, 9; Alegrias do lar, 8; Aliados, 7; Rato 22, 7; Milagres de Santo Antonio (drama), 6; Candinha, 6; Cá e lá, 5; Espetáculos variados, 5; Milagres de Santo Antonio (comédia), 3; Quincas Teixeira, 2; Genro do Caetano, 2; A noiva e a égua, 2; 39 da oitava, 2; Entre fidalgos, 2; Cinturão elétrico, 1; Fado e maxixe, $11^{2}$.

A lista é extensa, mas serve como uma amostra do gosto e preferência do público do início do século XX. Esse é o repertório da Companhia Arruda desde a sua fundação, em 1916, até 1918. Como se pode observar é um repertório variado, composto principalmente por comédias, dentre as quais se destacaram as revistas Uma festa na freguesia do Ó, São Paulo futuro, a burleta $O$ mambembe (grafada só Mambembe no periódico $A$ vida moderna) e a comédia-opereta $A$ capital federal.

\footnotetext{
${ }^{2}$ A vida moderna, n. 340, 25/07/1918, ano XIV.
} 
Apesar da concorrência estrangeira, a trupe do ator Arruda se manteve em atividade e conquistou um grande espaço nos palcos paulistas, trabalhando no teatro São Pedro, Colombo, e instalou-se por mais de um ano no teatro Boa Vista. Segundo a revista $A$ vida moderna, esse é um fato muito significativo:

Para que façam bem ideia dessa glória ou triunfo, basta advertir que as melhores companhias, sem excluir as mais ricas e suntuosas companhias estrangeiras, nunca puderam demorar-se num teatro, em S. Paulo, mais que dois ou três meses. As mais vitoriosas, aquelas que mais se apoderaram das simpatias e da afeição entusiástica do público, não esgotaram quatro meses de permanência num teatro. ${ }^{3}$

O ator Arruda era um estudioso do tipo caipira e um dos melhores no país. "Sem recorrer a atitudes e gestos artificiosos, simples, natural, o Arruda encarna o caipira com uma prodigiosa semelhança". ${ }^{4}$

O caipira é um tipo que veio de Martins Pena com as suas comédias de costumes e parece ser imortal, tal é o número de vezes em que aparece na nossa dramaturgia. O protagonista da revista $O$ recruta do 43, montada pela companhia Arruda, é um caipira que chega a São Paulo e encontra um recruta do 43, que lhe mostra a cidade - fórmula bastante utilizada pelos comediógrafos.

A imprensa hesitava ante o sucesso da Companhia: ao mesmo tempo em que festejava o êxito do grupo em um meio dominado por companhias estrangeiras, criticava o seu repertório. Encontram-se, nos periódicos, críticas favoráveis e desfavoráveis à Companhia Arruda. As desfavoráveis ficam por conta do repertório, composto principalmente pelo teatro ligeiro e musicado; as favoráveis veem no sucesso da Companhia a valorização do teatro nacional.

A importância da Companhia Arruda, portanto, foi além de sua popularidade junto ao público, já que impulsionou o teatro nacional. Ademais, propiciou a montagem de peças que fortaleceram o movimento nacional-regionalista, cujo intuito era combater a europeização, através da valorização dos elementos nacionais. Esse movimento também resgatava a simplicidade da vida no Interior, como um ideal a ser alcançado com toda sua inocência, em oposição à vida na Capital. E, conforme mencionado, Sebastião Arruda incorporou o protótipo do caipira ingênuo como nenhum outro.

Além das peças anteriormente citadas, em que Arruda obteve um bom desempenho, vale destacar Cenas da roça e Flor do sertão, do crítico, dramaturgo e jornalista Arlindo Leal:

\footnotetext{
${ }^{3}$ Idem.

${ }^{4}$ Idem.
} 
Flor do sertão está em cena não há ainda duas semanas; mas promete ser, como as Cenas da Roça, uma como nova pedra filosofal para a Companhia Arruda. Todas as noites atrai ao Boa Vista uma multidão de espectadores, que ali vão assistir ao triunfo de Arlindo Leal, dando-lhe todas as palmas que ele merece pelos seus muitos esforços em prol do levantamento do nosso teatro. ${ }^{5}$

$\mathrm{Na}$ burleta Gente moderna, de Francisco Barroso e Nascimento Filho, Arruda encarnou um tipo diferente de caipira: o caipira rico, o qual ainda não fora explorado pelos revisteiros e burletistas. O enredo apresenta um caipira que, entusiasmado por um bacharel, está disposto a lhe fazer todos os benefícios com a condição de que este lhe encontre uma noiva. Conforme $O$ pirralho, a peça, "com ares de alta comédia", foi um dos melhores trabalhos apresentados no Boa Vista 6 .

As críticas ao gênero musicado contradizem-se. A Revista do Brasil traz a seguinte descrição de uma revista de ano: "Um entrecho rudimentar põe em cena alguns compadres e certo grupo de figuras contemporâneas. Nada mais simples e para usar de usadíssimo plebeísmo, também nada mais besta..."7

Antonio Piccarolo, crítico da Gazeta artística, justificou a preferência do público a esse tipo de peça argumentando que os espectadores não possuíam formação e educação necessárias para apreciar o teatro literário. Aliado a isso, a rotina diária e o trabalho desgastante faziam com que as pessoas buscassem nessas formas de teatro a distração das ocupações cotidianas. Le' O Vaz, d' O Estado de São Paulo, alegava que os empresários se aproveitavam dessa situação para transformar o teatro em "aparelho de fazer rir", montando peças que tivessem o mínimo possível de ideias, mas que causassem cócegas necessárias "para sacudir as enxúndias abdominais das plateias numa gargalhada sacolejante". Ele completa: "Por isso o teatro nacional, mesmo galvanizado pelo esforço de Arthur Azevedo, nunca dará de si mais do que lhe compete: - as revistas e respectivos compadres, que são tudo quanto cabe dentro da nossa uberdade dramática" ${ }^{\text {. }}$.

Como foi dito anteriormente, o talento de Artur Azevedo não era negado, embora sua escolha dramatúrgica fosse questionada. O mesmo se dava com Martins Pena, cujas peças desfrutavam de mérito mais por seu valor histórico, segundo a crítica, do que pela qualidade do texto.

5 A vida moderna, n. 352, 12/02/1919, ano XV.

6 Opirralho, n. 248, 25/02/1918, ano VII.

${ }^{7}$ Revista do Brasil, n. 25, ano III, Vol. VII, janeiro de 1918. pp. 98-9.

${ }^{8}$ Idem, n. 39, ano IV, Vol. X, março de 1919, pp. 364-66. 
...o popular Martins Pena, inteligência culta, introduziu o teatro nas povoações escrevendo comédias de sabor local que, no gênero, (considerando-se a época) foram a mais alta expressão da arte brasileira e mesmo atualmente desfrutam de certo prestígio dado o seu valor histórico. ${ }^{?}$

O coro dos intelectuais afirmava, de um modo geral, que o nosso teatro não contava com bons escritores teatrais desde Alencar. Artur Azevedo e Martins Pena eram respeitosamente considerados, mas sempre com algumas observações sobre suas obras. Entretanto, havia algumas vozes dissonantes. Abadie Faria Rosa, autor de Nossa terra e Longe dos olhos, era uma delas. Perguntado se já tivemos um teatro nacional bom ou prometedor, ele responde que, apesar de nossa literatura ser pobre de escritores teatrais, havia três nomes que podiam ser apontados como verdadeiros escritores de teatro: Martins Pena, França Júnior e Artur Azevedo. Segundo ele, só as peças desses autores seriam representáveis, as demais não passariam de "diletantismo literário".

Os nomes de França Junior e Martins Pena também são citados por Arlindo Leal como grandes escritores ao lado de Plauto, Terêncio, Molière, Beaumarchais, Gil Vicente e Antonio José. Conforme artigo da revista Íris de 1905, o teatro ainda não apresentava seguidores à altura dos dois brasileiros, uma vez que o teatro "abastardava-se" cada vez mais, apesar dos esforços de Artur Azevedo (novamente citado com ressalvas). Aos autores que se dedicavam à carreira teatral, Arlindo Leal recomendou que "tratem de sanear" a arte e produzir peças de valor, seguindo os passos de Martins Pena e França Junior, os quais nacionalizaram a cena, retratando nossos usos e costumes. Caso isso não ocorresse, e os autores cedessem à ganância dos empresários, que montavam peças de valor duvidoso, as seguintes frases de Álvares de Azevedo se tornariam verdadeiras: "A farsa embotou o gosto e matou a comédia. O palhaço enforcou o homem de espírito. Arlequim fez achar insípido Tartufo" ${ }^{\prime 10}$.

É interessante notar que Arlindo leal parecia não ter uma ideia definida sobre Artur Azevedo. No artigo citado anteriormente da revista Íris, ele lembra o nome do comediógrafo, mas não o coloca ao lado de Martins Pena e França Junior, como grandes escritores brasileiros. Entretanto, em um artigo de 1906, da mesma revista, Arlindo Leal se refere a Artur Azevedo como o "mestre dos mestres": "Urge, pois, que nos esforcemos para o renascimento do teatro nacional, seguindo o bom exemplo e os conselhos daquele que é, entre nós, o mestre dos mestres - Arthur Azevedo" ${ }^{\prime 11}$.

\footnotetext{
${ }^{9}$ Correio musical brasileiro, n. 1, 1-15 de maio de 19251, p. 12.

${ }^{10}$ Revista Íris, n. 1, Vol I, novembro de 1905, pp. 19-21.

11 Revista Íris, Vol. I, 1906 (não está datada), pp. 148-150.
} 
Certamente essa indecisão se dá pelo fato de Artur Azevedo ser autor de revistas, burletas e operetas. O próprio Arlindo Leal confessa ter escrito revistas de ano, mas se mostra arrependido por ter cometido este "pecado". É desse autor a revista de ano pioneira em São Paulo, O boato. A peça passava em revista os acontecimentos dos anos de 1897 e 1898. O seu fio condutor retratava um casal de caipiras, vindo de Araras, interior de São Paulo. O casal, Quitéria e Anastácio da Sapucaia, chegava à capital com a filha Dorinha para assistir ao carnaval. À medida que conhecem a cidade grande, metem-se em grandes confusões.

A respeito das operetas encenadas naquele momento, Arlindo Leal diz que elas "ressentem-se do mesmo vício" das revistas de ano:

Ferem o ouvido dos assistentes com frases de baixo calão; o jogo de espírito é substituído por trocadilhos chulos; as frases veladas ou ambíguas desaparecem, surgindo os apartes livres, em conjunto com a exibição aparatosa e ridícula, a um tempo, de verdadeiros quadros vivos. ${ }^{12}$

Se a crítica hesitava, o público e as companhias teatrais não tinham dúvidas sobre o talento de Artur Azevedo. Em julho de 1908, a famosa atriz italiana Tina di Lorenzo subiu aos palcos com a peça $O$ dote, de Artur Azevedo, interpretando o papel principal. A montagem alcançou estrondoso sucesso.

Nas duas primeiras décadas do século XX, os escritores que conseguiram destaque foram, em sua maioria, autores de revistas e operetas: Danton Vampré, João Felizardo, João Phoca, Luís Galhardo, Alexandre Azevedo, entre outros. Considerados hoje como autores menores, não são muito estudados, visto também que não há registro de suas obras. Mas alguns ficaram para a posteridade, como é o caso de Juó Bananére, autor de $A$ Divina encrenca, e João do Rio, que teve seu valor reconhecido já na época, como "finíssimo observador, e cultor notável da psicologia urbana". A estreia de sua comédia Eva, em 13 de julho de 1915, no Teatro Casino Antártica, foi muito comentada nos meios jornalísticos, merecendo um longo artigo de Oswald de Andrade, em que escreveu:

Poder-se-ia desejar melhor para o teatro nacional em começo? Creio que não apesar da opinião mal redigida mas firme do cronista do Diário Popular. Erra por toda a peça um sutil simbolismo. E como simbolismo em comédia haverá melhor do que a bela, a forte, a inteligente intriga que João do Rio inventou? Será difícil. Em Eva há toda a fábula linda da mulher. ${ }^{13}$

${ }^{12}$ Idem, vol. I, pp. 192-195.

13 Opirralho, n. 196, 17/07/1915. 
Oswald de Andrade, por sua vez, antes de se consagrar como poeta modernista e autor de peças com amplo teor social, escreveu em parceria com Guilherme de Almeida, em 1916, Mon coeur balance e Leur âme, que foram muito elogiadas. Ganharam destaque nas revistas literárias como obras de grande valor, mas pouco a pouco os elogios foram sendo trocados por críticas, por terem sido escritas em francês.

Mon coeur balance foi definida por Dolor de Brito como uma "comedio-drama, moderna, real e encantadora" ${ }^{14}$. Eis o que diz O Estado de São Paulo sobre a peça:

A comédia (cremos não errar chamando-lhe assim) é em quatro atos e escrita em francês. Por que em francês? Perguntará o leitor, intrigado, achando que um Almeida e um Andrade, escrevendo no Brasil, para brasileiros, estavam na obrigação de escrever na língua deles e do país. (...)

Dizemos apenas que eles são moços, quase uns meninos, e que o verdor dos anos explica essa e outras extravagâncias..$^{15}$

O enredo gira em torno de um casal, Gustavo e Marcela, que se conhece na praia, em meio a um mundo de frivolidades. Luciano, amigo do rapaz, tenta dissuadi-lo desse namoro, falando-lhe coisas graves acerca do casamento. No entanto, Luciano passa a cortejar Marcela e acaba por ser correspondido. Descoberta a traição, Gustavo se enfurece. Porém, como o coração da moça balança e não pende definitivamente para nenhum dos lados, ela termina só e os amigos se confraternizam, fazendo as pazes.

Ao que parece, a comédia agradou aos intelectuais de $O$ pirralho, revista fundada com a colaboração de Oswald de Andrade. "A tessitura da comédia, o corte das cenas, a individualidade dos personagens, o diálogo, tudo revela grandes disposições para esse gênero de literatura"16.

Mas O queixoso, revista de grande consumo no meio intelectual, se limitou a dizer que a peça não era má, após uma crítica em que acusava os autores de serem cabotinos, que não teriam causado tanto barulho em torno de seus nomes se tivessem escrito a peça em português, e por isso optaram por escrevê-la em francês.

Na noite de 16 de dezembro de 1916, em honra à memória de Emile Verhacren e em homenagem a alguns escritores brasileiros, a atriz Suzanne Després e o Sr. Lugné Poe realizaram a leitura de uma parte de Leur âme no Teatro Municipal.

\footnotetext{
14 O pirralho, 08/01/1916.

15 O pirralho, 08/01/1916, sem numeração de página.

${ }^{16}$ Idem.
} 
Além dessas peças, a edição de $O$ pirralho de 02/05/1916 traz a informação de que Oswald de Andrade e Guilherme de Almeida estavam concluindo outra comédia, $A$ escalada, dessa vez escrita em português.

Fora também do circuito das revistas e operetas, Claudio de Souza mereceu a atenção da crítica. Segundo O pirralho, a sua comédia Flores de sombra foi sem dúvida o maior sucesso de 1916 e um dos primeiros trabalhos teatrais brasileiros ${ }^{17}$. A peça foi encenada pela companhia de Leopoldo Fróes no teatro Boa Vista. Fizeram parte do elenco: Apollonia Pinto, Colás, Amália Capitani, Cecília Neves, Emygdio Pereira, Elvira Pinho, Ema de Souza, Interior Campos, Britto e Leopoldo Fróes.

Era esse o tipo de peça que os críticos esperavam dos nossos escritores teatrais, ou seja, uma comédia feita "nos moldes do bom e do são teatro". Isto é, uma peça sem palavras chulas e sem o duplo sentido, tão presente nas revistas.

Flores de sombra é uma comédia escrita em linguagem castiça, sem uma única frase que possa escandalizar ao mais pundonoroso ouvido, e veio prevãs que o pretenso desvio do gosto estético do público é uma pura ficção, com que empresários poucos dignos desse nome, procuram esconder sua ganância, na exploração do dito chulo e da revista imoral. Nenhuma peça tem dado maior número de representações em S. Paulo, do que As Flores de sombra, que no entanto é feito dentro dos moldes do bom e do são teatro. ${ }^{18}$

Observa-se, entretanto, que essas peças - Mon coeur balance, Leur âme, Eva e Flores de sombra - não correspondiam ao repertório predominante da época, apesar da notoriedade conquistada.

\section{Considerações finais}

No início do século XX, o teatro brasileiro apresentava o seguinte quadro: de um lado as companhias estrangeiras representando dramas e as chamadas peças "sérias", assim consideradas por apresentarem lições de moral ou paradigmas do certo ou errado na sociedade. De outro, os escritores brasileiros, em sua maioria, trabalhando com as formas do teatro cômico e musicado.

Esse panorama era alvo de críticas negativas. Os críticos do período acreditavam que o teatro nacional vivia uma crise. Para eles, além de as companhias estrangeiras não representarem a realidade de nosso povo, as peças nacionais que prosperavam não eram de

17 O pirralho, n. 229, 31/12/1916, sem numeração de página, ano VI.

18 O pirralho, n. 229, 31/12/1916, ano VI, sem numeração de páginas. 
qualidade. Porém, eles associavam qualidade dramatúrgica a temas que moralizassem a sociedade ou servissem para redimi-la de seus erros. Dessa maneira, repetiram durante anos e anos que o teatro de revista, as operetas e burletas foram responsáveis pela decadência do teatro brasileiro. Isso se agravou com a perpetuação dessa tese, consolidando- a, a ponto de deixar lacunas nos livros de história do teatro brasileiro.

A rivalidade entre o teatro musicado e o "sério" era o mote predominante das críticas presentes nas revistas pesquisadas, e os termos decadência, crise e morte do teatro eram constantes. Conforme $A$ vida moderna, o teatro nacional estava atacado pela "revistomania", já que nossos autores apreciavam verdadeiramente esse gênero. ${ }^{19}$

A comédia brasileira, portanto, viveu sob o reinado do teatro ligeiro, apresentando, vez ou outra, autores que fugiam a esse gênero, como Cláudio de Souza e João do Rio.

É interessante notar também que os críticos protestavam contra as produções estrangeiras e aspiravam a um teatro com assuntos nacionais. Essa questão do nacionalismo na arte perdurou por todo o início do século XX. Há textos de 1905, por exemplo, quando Arlindo Leal acusa ver em cena somente produções francesas, até de 1920, como o artigo $O$ nacionalismo na arte, o qual traz reclamações de que "O artista nacional é a eterna vítima indefesa dos rivais estrangeiros" ${ }^{20}$.

Almejava-se, portanto, um teatro nacional, que representasse a realidade de nosso povo, mas não se considerava a revista com seus caipiras e alegorias brasileiras, tampouco as piadas feitas de motivos políticos e a evolução da música nacional, elemento importante do teatro de revista.

Dentre os autores do teatro musicado merecem destaque Danton Vampré, o ator Arruda, João Phoca e Alexandre Azevedo e, certamente, o grande Artur Azevedo.

Das sessenta peças montadas pela companhia Arruda, as três que obtiveram maior sucesso são de autoria de Danton Vampré: São Paulo futuro, Sustenta a nota e Freguesia do Ó. Danton Vampré foi aclamado pela imprensa da época por ser um autor talentoso (apesar do gênero ao qual se dedicava), cujas vitórias como "revistógrafo" e autor de burletas não haviam sido superadas por ninguém.

Alguns críticos insistiam que os nossos dramaturgos se dedicavam ao teatro musicado porque haviam se rendido ao lucro garantido. Verdade ou não, o fato é que eles optaram pela comédia nas duas primeiras décadas do século XX.

É importante ressaltar que os intelectuais e críticos desse período não consideravam a comédia um gênero menor que o drama. A crítica direcionava-se ao teatro musicado e 
seu palavreado chulo e, muitas vezes, pornográfico; linguagem ambígua, com forte conotação sexual; e a perda do conteúdo moralizante de antes. Flores de sombra, de Cláudio de Souza, por exemplo, é uma comédia fora do gênero musicado que teve boa recepção de crítica e público.

\section{BIBLIOGRAFIA CITADA:}

PRADO, Décio de Almeida. História concisa do teatro brasileiro. Edusp, São Paulo, 2003.

A vida moderna (n. 340, 25/07/1918, ano XIV; n. 352, 12/02/1919, ano XV; n. 377, 20/05/1920, ano XVI).

Íris (n. ${ }^{\circ}$ 1, Vol. I, novembro de 1905; Vol. I, 1906).

Correio musical Brasileiro ( $\mathrm{n}^{\circ} 1,1-15$ de maio de 1925).

O pirralho (n. 248, 25/02/1918, ano VII; n. 196, 17/07/1915; 08/01/1916; n. 229, 31/12/1916).

Revista do Brasil (n. 25, ano III, Vol. VII, janeiro de 1918; n. 39, ano IV, Vol. X, março de 1919, n. 55, julho de 1920).

Abstract: Much has been commented in the literary magazines of the beginning twentieth century about the decadence of the Brazilian theater. One of the reasons for this impoverishment was credited to the musical theater and operettas. These genres, provoking easy and "digestive" laugh, according to critics, distanced the theater from its civilizing role. The aim of this paper is to contribute to the discussion that refutes this claim about the decay of the Brazilian theater. It's impossible to consider the theater decline when, reading São Paulo's literary magazines from the beginning of the twentieth century (19011922), we found many criticisms of theatrical shows and ads. They weren't, in most cases, the plays valued by the critics of the time, but belong to the Brazilian theatrical history and, now we know, had its value.

Keywords: musical theater; comedy; Brazilian theater. 